\title{
KIERKEGAARD y SCHMITT: VASOS COMUNICANTES ${ }^{1}$
}

\author{
Oscar Ortega Espinosa \\ Universidad Nacional Autónoma México
}

\section{Resumen}

En este artículo se presentan las analogías y nexos entre el pensamiento del teólogo danés Søren Kierkegaard y el jurista alemán Carl Schmitt, mostrando sus afinidades y sus divergencias. Primero, se expone la influencia de Kierkegaard sobre el autor prusiano. Segundo, se investigan las razones por las cuales el jurisconsulto germano omitió mencionar la contribución del teólogo dinamarqués a su obra, mientras se alude al rechazo por parte del primero de cualquier postura romántica o desinteresada de lo político; por último se estudian las limitaciones que tanto Kierkegaard como Schmitt tienen para presentar un horizonte ético distinto del presentado por el pensamiento liberal.

Palabras clave: Teología política, voluntad, estado de excepción, ética, soberanía.

\section{Abstract}

In this article, we point out the affinities and relationships between the thinking of the Danish theologian Søren Kierkegaard and the German jurist Carl Schmitt, underlying their commonplaces and their differences. Firstly, it is pointed out the occult relationship between Kierkegaard and the German writer. Secondly, we look for the reasons why Carl Schmitt hesitated to cite Kierkegaard as an important source for the building of his thinking by remembering the hate the former author had against all kinds of non-political or romantic positions. Finally, the limitations of Kierkegaard's and Schmitt's ethical philosophies to escape from the moral horizon of liberalism are underlined.

Keywords: Political theology, will, state of exception, ethics, and sovereignty.

Durante su vida el ser humano toma diariamente un sinnúmero de decisiones. Desde aquéllas más baladíes hasta las más relevantes. Todo esto en medio de la inexorabilidad del tiempo y con el apoyo (o la disuasión)

${ }^{1}$ Recibido el 21 de mayo de 2020; aceptado el 17 de junio de 2020. 
del marco espacial y contextual en el cual vive. La realidad de la finitud del hombre, a pesar de permanecer oculta, tarde o temprano sale a la luz y deja al sujeto aturdido, sobrecogido de espanto. Bien sabemos que el tiempo se desliza y cualquiera de nosotros teme que se le escurra de las manos. Uno siente el agobio de ver su más íntima posesión desaparecer; nadie puede dejar de gastarlo por más que lo evitemos. Es curioso que si bien alguien puede ahorrar el dinero hasta llegar a la avaricia; no ocurre lo mismo con el tiempo; incluso en el afán de retenerlo, lo perdemos irremediablemente. En nuestra época, donde cualquier referencia a lo trascendente, o a un fin superior al individuo, ha desaparecido, es paradójico notar que la gente se encuentra más obsesionada con la rapidez. El tiempo se fuga; sienten las personas que su vida se les escapa, porque bien sabemos que cuando ellas dicen que no tienen tiempo para emprender algo quieren realmente decir que prefieren aquéllas gastar su vida para un objetivo más apetecible.

Por la falta de un telos superior que su propia individualidad, la gente está frenética, y corre sin razón a todos lados porque teme que la inacción sea peor que el no tener un destino en mira. Es mejor que la barca navegue a ningún lugar a que permanezca en puerto ¿Acaso se gasta más si se mantiene un avión en tierra a que volara éste incesantemente? Para colmo el cálculo económico rige nuestra administración del tiempo. Reza el dicho: "el tiempo es oro"; yo creo, sin embargo, que ni siquiera puede valorarse objetivamente aquél con un precio igual al de la antimateria. El problema es que si uno tuviera el mundo como propiedad no habría operación comercial suficiente para ganar ni siquiera un segundo más de vida. Puede haber engaño en esos discursos del carpe diem, porque nunca te dicen qué es lo suficientemente valioso como para gastar tus energías en él. Al final aquéllos ocultan una moral hedonista, que nunca te permitirá decidir en los momentos de tensión, o de extrema necesidad.

Justamente esta falta de baremos para decidir ante un estado más allá de lo normal es producto de un vacío, que se ha querido sustituir con una rapidez cada vez más estrepitosa. Si bien Byung-Chul Han ha estudiado más esta aceleración hordiana, este mal ya había sido objeto de la reflexión de Ernst Jünger, quien alertaba que "retrotrae la invención de máquinas cada vez más rápidas a la voluntad de huida, a una especie de instinto con el que el hombre presiente amenazas de las cuales quizá puede salvarse a gran velocidad yendo de una parte a otra de la tierra" 2 . La fuga, que busca enmascarar la falta de un centro para confrontar la realidad, debe, por tanto,

${ }^{2}$ Ernst Jünger, "Sobre la línea” en Jünger, E., y Heidegger, M., Acerca del nibilismo, Barcelona: Paidós, 1994, p. 41. 
ser cada vez más rápida; sólo así la angustia parece eliminarse. Empero, cuando llega el momento de la gran confrontación, la persona se desmorona.

Nadie tendría que escoger en momentos de máxima tensión si no estuviera en una situación de crisis, cuya irresolución o pérdida de rumbo implicaría el mal mayor. Sin embargo, la resolución que se tome, cualquiera que sea ésta, hará supurar las heridas con un pus tanto físico como espiritual tan grande, que es claro que no a cualquiera le es dado por el Cielo enfrentarse a situaciones así. Es fácil criticar a las personas cuando sus decisiones más fundamentales yerran, haciendo alarde de un mejor juicio. Cierto es que hay otros criterios para decidir en el día a día, e incluso en los momentos más terribles del humano existir. Sin embargo, una cosa es el conocer, y otra el actuar, y es justo en la voluntad donde la mayoría cae presa de la desidia.

Respecto de los criterios para tomar una decisión, tres visiones de los actos morales parecen sobresalir por lo general en los debates contemporáneos, a juicio de Alasdair MacIntyre, según su gran obra Tras la virtud: la emotivista (hedonista), la aristotélica o de los valores y la sofocliana o trágica; es en esta última donde se encuadran las visiones de Søren Kierkegaard y de Carl Schmitt. Entre estos dos pensadores parecía haber una falta absoluta de relación; uno incluso duda de que pueda existir siquiera una relación de lectura, donde el segundo, que nace años después de la muerte del primero, leyera las obras del autor danés. Pero, la realidad supera cualquier presuposición.

No obstante, ¿no estoy creando relaciones entre estos dos autores tan antitéticos entre sí? ¿Hay acaso alguna afinidad, conexión o vaso comunicante entre ellos? Podría sonar hasta espeluznante la afirmación de que hay algún nexo entre el solitario teólogo danés y el jurista alemán filonazi. No obstante, existen ciertos vasos comunicantes, los cuales entrelazan las ideas de ambos autores germanos. A pesar del tiempo que los separa, se pueden establecer puentes entre sus cosmovisiones.

Para la exposición de las relaciones entre ambos autores, el estudio se enfocará primeramente en el estudio genealógico de algunos conceptos de la teoría política de Carl Schmitt, después se concentrará en observar las afinidades y repulsiones que tuvo el pensador alemán para con el teólogo danés y, por último, se enfocará en la piedra de tropiezo de ambos, al menos en el terreno ético: la imposibilidad de superar el horizonte ético del liberalismo. 


\section{El asco de la decisión}

El primer punto de contacto entre ambos autores es el papel dado por ambos tanto a la angustia como al asco de la resolución moral. El carácter trágico de la toma de decisiones recorre la obra de Kierkegaard y él la resuelve, a falta de un referente más allá de la moral, con la nuda voluntad. El pensador danés destaca ese elemento ignorado para el conocer que es el interés, es decir la voluntad, frente al papel omnicomprensivo de la razón otorgado por gran parte de la filosofía de la época, sobre todo por la filosofía hegeliana, movimiento que se había apoderado de las mentes más preclaras de Dinamarca de aquel entonces.

Sus reflexiones al respecto son explícitas en su obra Jobannes Climacus o el dudar de todas las cosas. En este libro Kierkegaard hace un estudio, con el seudónimo de Johannes Climacus, nombre de un antiguo teólogo griego, de su propio recorrer filosófico desde la negación mayor que es dudar del todo. Divide la disquisición en tres enunciados, que son los siguientes: 1) La filosofía comienza con la duda; 2) Uno tiene que haber dudado para llegar a filosofar, 3) La filosofía moderna comienza con la duda"3. Este periplo lleva al pensador a creer que es la conciencia, como centro de confluencia del mundo de las ideas y del mundo de los hechos o realidad, donde surge la duda, y por tanto se encuentra uno ante la voluntad por conocer, el interés ${ }^{4}$.

Para el danés, el individuo es un punto de confluencia entre el mundo ideal o de las ideas, denominado en algunas traducciones, como idealidad, y el mundo de los objetos, o realidad. "Una duplicidad semejante tiene necesariamente dos expresiones. La duplicidad es la realidad y la idealidad, la conciencia es la relación", es decir el individuos.

Esta posición del ser humano como puente permite más no moviliza a aquél a reflexionar sobre sí mismo y sobre el mundo en el que vive. Más bien, el individuo toma conciencia de sí cuando surge primero una contradicción entre ambos mundos, que lleva al sujeto, posteriormente, a tratar de encontrar la causa de la disonancia cognitiva. Este elemento es puramente subjetivo y no es otro que la voluntad.

El proceso de autoconciencia surge de una contradicción, producto del choque de dos realidades. El filósofo danés lo expone de este modo: "La inmediatez es la realidad, el lenguaje es la idealidad, la conciencia

${ }^{3}$ Søren Kierkegaard, Johannes Climacus, o De todo hay que dudar, trad. de Javier Teira Lafuente, Barcelona: ALBA, 2008, p. 50.

${ }^{4}$ Ibíd., p. 142.

${ }^{5}$ Ibíd., p. 100. 
es la contradicción. En el instante en que yo expreso la realidad se da la contradicción, porque lo que yo digo es la idealidad" "6. Sin el individuo como puente es claro que...

En la mera realidad no hay ninguna posibilidad de duda; en el momento en que la expreso en el lenguaje, la contradicción está ahí, pues yo no la expreso en absoluto, sino que produzco algo distinto. En la medida en que lo dicho es algo de mi producción, he puesto ésta en relación con la idealidad; en la medida en que lo dicho es algo de mi producción, he puesto la idealidad en relación con la realidad ${ }^{7}$.

Una figura análoga a la voluntad dentro del individuo desempeña el mismo papel dentro del aparato estatal. El soberano, quien decide en momentos de especial peligro para la República según la teoría jurídico-política de Carl Schmitt, toma una resolución tan trascendente que ejerce un influjo tal que su sustento jurídico o político queda más allá del escrutinio de los pueblos. Además ¿qué tendrían éstos que inquirir al soberano si fue justamente su desidia o su incompetencia la que condujo a la crisis? Por eso el jurista alemán, como muchos hombres de su época admiraban a los Césares que surgían de entre las masas, destacándose de entre ellos, un maestro rural, de curiosa trayectoria y también un joven cabo, que tuvo a bien luchar por otra patria diferente de la suya; nos referimos tanto a Benito Mussolini como a Adolfo Hitler. Las democracias, en aquella época, no habían servido para nada, y se requería, a juicio de varios grupos, una sacudida tremenda en el cuerpo de los estados.

La conexión más profunda entre estos dos pensadores germanos es una relación donde el danés insufló a Schmitt con nociones que permitieron a éste concebir su teología política, con sus conceptos más polémicos. En su gran trabajo Teología política el alemán habló de la excepción como explicación de lo general y de aquella misma, en la parte final del primer capítulo de este libro:

La excepción explica lo general y se explica a sí misma. Y si se quiere estudiar correctamente lo general, no hay sino mirar la excepción real. Más nos muestra en el fondo la excepción que lo general. Llega un momento en que la perpetua habladuría de lo general nos cansa; hay excepciones. Si no se acierta a explicarlas, tampoco se explica lo general. No se para mientes, de ordinario, en esta dificultad, porque ni siquiera sobre lo general se piensa con

${ }^{6}$ Ibíd.

${ }^{7}$ Ibíd. 
pasión, sino con una cómoda superficialidad. En cambio, la excepción piensa lo general con enérgica pasión ${ }^{8}$.

El extracto lo atribuye el jurista alemán a un interesante teólogo9. Por parte de cierta bibliografía, se considera que esta cita fue redactada por Schmitt, pero se ha descubierto que alude a ideas expresadas en el libro La repetición, escrito por Kierkegaard. Para el danés, ésta es una nueva fundación de sentido, que se aleja del recuerdo pagano. También es una apertura a la trascendencia; y un punto donde se entrecruza lo infinito con lo finito. Incluso se puede ver la excepción como contradicción y confirmación de lo general, al igual que la ventana de lo individual, de lo particular en el hombre, que lo diferencia, ante Dios, de otros seres humanos, y que evita que caiga en la masa indiferenciada de la bumanidad. Por tanto, Kierkegaard, en el plano individual, inspiró a Schmitt para concebir la excepción y el carácter trágico de las decisiones soberanas.

Para la comprensión de la influencia de Kierkegaard sobre el jurista alemán es menester comprender la magnitud de la obra desarrollada por este último: la teología política. Será esta última donde Kierkegaard aportará más elementos teóricos, sin menospreciar tampoco su contribución a la teoría jurídica schmittiana.

\section{Teología politica: estudio genealógico de los conceptos de la teoría del Estado}

La teología política, según Carl Schmitt, trata de explicar las raíces teológicas del ejercicio político. Y producto de su investigación, descubre en algunos términos la influencia profunda de ideas religiosas en las visiones políticas contemporáneas. Esto no podía dejar de ser menos cierto de la institución del soberano. Cabe mencionar que la teología política: "no implica necesariamente una identidad de sustancia entre la teología y lo moderno, ni una perfecta identidad de significado entre los conceptos teológicos y los conceptos políticos; se trata, más bien, de una relación estratégica particular, que marca los conceptos políticos, remitiéndolos a su origen teológico" ${ }^{10}$.

${ }^{8}$ Carl Schmitt, Teología política, trad. de Francisco Javier Conde y Jorge Navarro Pérez, Trotta, Madrid, 2009, p. 20.

${ }^{9}$ Ibíd.

${ }^{10}$ Giorgio Agamben, El reino y la gloria, trad. de Flavia Costa, Edgardo Castro y Merces de Ruvituso, Buenos Aires: Adriana Hidalgo editora, 2008, p. 18. 
Esta línea de investigación tiene sustento porque, según Carl Schmitt, "todos los conceptos de civismo de la moderna doctrina del Estado son conceptos teológicos secularizados"11. Al respecto, Giorgio Agamben nos explica que la secularización no es una etapa de superación de los escenarios mitológicos y metafísicos, como dijera Augusto Comte, ni "un concepto sino una signatura en el sentido de Foucault y Melandri (...) es decir, algo que en un signo o en un concepto lo marca y lo excede para referirlo a una determinada interpretación o a un determinado ámbito, sin por ello salir de lo semiótico para constituir un nuevo significado o un nuevo concepto ${ }^{12 "}$. Para una mayor comprensión, leamos lo que menciona Emmanuel Taub sobre el tema: "La secularización es este corrimiento de los conceptos que se da, ante todo, como un acto lingüístico por el cual se traslada o re-significa un concepto que pertenecía al ámbito de la teología hacia el ámbito de la teoría del Estado, o sea, hacia el ámbito de la política"13.

Sin embargo, este corrimiento o resignificación no lleva consigo naturalmente un vaciamiento o desaparición del sustrato teológico o divino que reside dentro del concepto resignificado por el solo hecho de pensarlo ahora en el ámbito político. Más aún, con sólo pensar en el origen conceptual y lingüístico de los conceptos políticos a través de la historia universal que llega a nuestro mundo moderno desde la Antigüedad del Imperio Romano y su articulación con el Cristianismo, se hace imposible pensar en la desaparición del sustrato teológico de los conceptos políticos de forma absoluta y determinante. Por lo que nos gustaría sugerir que las huellas teológicas continúan presentes allí, moldeando desde las oscuridades de los caminos transitados y olvidados por el bosque de la historia, los conceptos políticos 'supuestamente' secularizados ${ }^{14}$.

Emmanuel Taub señala las potencialidades de esta labor genealógica, producto de revelar al público el malestar pero a la vez la influencia que ejercen los conceptos de la filosofía política:

[...] lo que intentamos señalar es que el problema moderno de los conceptos de la teoría del Estado, y con ello de la política, ha abandonado la importancia de la convivencia de lo teológico y lo político al imaginar y construir la institucionalidad estatal y gubernamental desde la base de la razón humana,

${ }^{11}$ Ibíd., p. 16.

${ }^{12}$ Ibíd., p. 18.

${ }^{13}$ Emmanuel Taub, "Teología política, angelología y antropomorfismo: el problema de la secularización en el judaísmo" en Síntesis. Revista de filosofía 2020; no. 2, 2019, pp. $134-135$.

${ }^{14}$ Ibíd., p. 135. 
operativa como libre de elementos incognoscibles e inexplicables, cuando justamente el malestar que producen (así como el secreto de su legitimidad) al pensamiento racional moderno se debe a que nunca han perdido vinculación con la dimensión de lo divino o de lo teológico ${ }^{15}$.

Es decir, la teología política, además de su labor genealógica respecto de los conceptos de la teoría del Estado, también revela el punto ciego de éstos al mostrar el componente carismático o irracional que les otorga relevancia incluso en épocas sumamente desvinculadas de las iglesias organizadas. Si bien ha habido un cambio en el modo de comprender los conceptos, éstos mantienen su contenido simbólico. En esta tesitura, en Occidente, la figura del soberano, que alcanza su culmen en la figura del monarca absoluto, es susceptible de ser sometida a una revisión profunda, donde sus nexos con otras ideas puedan ser explicitados.

\section{El soberano: concepto nodal de la teología política schmittiana}

La teología política busca, como quedó consignado líneas arriba, conocer la génesis de los conceptos políticos en la edad de la secularización. Para el jurista alemán Schmitt, la raíz de varios de estos términos se retrotrae a la teología. Bajo esta línea, el pensador germano da un sentido similar al término excepción, y con él logra concebir la idea del soberano, que es la persona que decide en los momentos donde la normatividad vigente queda en suspenso, y no queda otra solución sino tomar una decisión relevante para acabar con el estado de malestar en el que se halla el orden político.

La excepción y el gesto del soberano, que preparan la instauración de un nuevo orden o la refundación del anterior, constituyen una bisagra entre lo jurídico y lo político; esto culmina en el acto constituyente del orden jurídico de una sociedad determinada. Recordemos que Schmitt sostenía una lucha a ratos soterrada, a ratos abierta, por acabar con esos esquemas formales que describían al Derecho como un sistema cerrado, y que acercaban a éste a la visión diletante liberal, de un orden que, autopoiético, se replica a sí mismo, sin recurrir a ninguna realidad superior o trascendente. Esa asfixia, que genera en ciertas personas el concebirse parte de un todo que parece explicarlo a uno sin fisuras, es un atributo que comparten tanto el danés como el alemán.

${ }^{15}$ Ibíd. 
El liberalismo, con sus esquemas cerrados, parece temer lo excepcional, no por nada advierte Schmitt la repulsa de los liberales a permitir un gesto de soberanía, al limitar los alcances del estado de excepción. Los liberales, como denunciara ya Juan Donoso Cortés, quieren oxímorons jurídicos y políticos: gente que gobierne, pero no decida; resolver los problemas, pero seguir en lo mismo. Lo individual, ya sea como choque que causa desesperación en la persona pero que le da una conciencia de sí, producto ya del choque entre la idealidad y la realidad, ya del choque entre lo infinito y lo finito en el hombre, ya como un momento fundacional que rompe con lo establecido, es el eje que permite comprender el pensamiento de ambos autores. Pero lo individual, a partir del elemento volitivo, anula las referencias a las realidades externas y permite la constitución del decisor, ya personal, ya político. Recordemos: la excepción y la repetición son los medios por los cuales la singularidad se manifiesta y donde los grandes moldes; las ideologías o los órdenes normativos quedan barridos. Para horror de las grandes narrativas, la individualidad es inseguridad, es abertura, pero a la vez rompimiento, pérdida de coherencia.

En el hegelianismo, como en otras filosofías superadoras de las contradicciones, uno florece, uno eclosiona, por tanto, no existe realmente. Parecido al Universo que brota de un huevo primigenio, según la cosmología hindú, el individuo surge del todo indiviso, como una protuberancia más de lo general. El sujeto es un grano más, un detalle curioso que se ignora ante el espectáculo del bosque. Para Schmitt como para Kierkegaard, tales narrativas eliminan a la persona.

El factor individual y el peso de sus decisiones permean la obra de ambos autores. En lo político, desde la visión del jurista germano, el dictador soberano sería, analógicamente, el caballero de la fe, porque a pesar de vincularse a lo general, al crear un nuevo orden, abre la puerta a un momento fundacional, en el cual lo general de lo ético (y en el caso del soberano, de lo normativo), se diluye. El estado de excepción schmittiano puede tener más que ver con la figura del caballero de la fe que con la del héroe trágico, que al final tiene la excusa de lo general para actuar, sin embargo ¿qué situación aparece cuando se crea un nuevo orden? El dictador comisarial que busca preservar el viejo statu quo es más bien como Agamenón, sacrifica lo particular ante lo general, en la lógica schmittiana, los derechos y libertades de un entramado político; mientras que el dictador 
soberano crea un nuevo sistema, apelando a lo superior, para escapar de la parálisis provocada por las instituciones que rigen el sistema ${ }^{16}$.

Lo ético es en cuanto tal lo general y en cuanto general válido para todos. Lo podemos expresar también desde otro punto de vista, diciendo que es lo válido en todo momento. Reposa, inmanente, en sí mismo no tiene nada

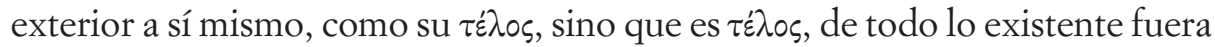
de ello, y una vez que lo ha tomado para sí no puede ya ir más lejos ${ }^{17}$.

Algo similar pasa con lo jurídico, que se cierra en sí mismo, y encuentra su finalidad en ello mismo, al menos desde la perspectiva del derecho positivo en los últimos dos siglos: una normatividad que se sustenta en su propia validez formal y que no recurre a finalidades superiores o extrañas al mismo cuerpo jurídico. El individuo tanto en el orden ético como en el jurídico se sacrifica en pro de lo general ${ }^{18}$. En esta tesitura, como diría el anarquista Max Stirner en El único y su propiedad, uno se ve subsumido por los sistemas, que no tienen escrúpulos en sacrificarlo. No es menor el horror de verse eliminado por el sistema, ya sea el ídolo ante el cual el individuo es sacrificado la Razón, el Hombre, la Humanidad o Dios.

Kierkegaard subraya, líneas abajo, el carácter insidioso y hostil de lo particular, del individuo frente a lo general. "Y cada vez que el Particular se reivindica en su particularidad frente a lo general, peca, y sólo reconociéndolo de nuevo puede reconciliarse con lo general" ${ }^{19}$. Posteriormente, el teólogo danés resalta el estado anímico surgido en cualquier individuo que se atreve a ir en contra de lo establecido, con el grado de tensión y dolor que esto provoca: "Cada vez que el individuo, después de haber ingresado en lo general, siente una inclinación a afirmarse como el Particular, cae en una Anfregtelse de la que únicamente podrá salir si arrepentido, se abandona como Particular en lo general" 20 .

El elemento volitivo en Kierkegaard enfatiza, en contra del hegelianismo y de los grandes sistemas al individuo. La razón no permite el conocer, esto procede del carácter subjetivo del cognoscente, quien tiene un interés en

${ }^{16}$ Carl Schmitt, La dictadura, desde los comienzos del pensamiento moderno de la soberanía hasta la lucha de clases proletarias, trad. de José Díaz García, Madrid: Revista de Occidente, 1968, pp. 28-29, 182-183.

${ }^{17}$ Søren Kierkegaard, Temor y temblor, trad. de Vicente Simón Merchán, Madrid: Tecnos, 2000, p. 45.

${ }^{18}$ Ibíd.

${ }^{19}$ Søren Kierkegaard, Temor y temblor, p. 45.

${ }^{20}$ Ibíd. 
aprehender la cosa. Lo cual lleva a un desafío que da claridad a un proceso de autoconciencia; análogamente la situación de excepción imprime la conciencia de su soberanía a su detentador. En ambos casos la conciencia es la bisagra entre el reino de lo ideal y el reino de lo real, y es a través del cuestionamiento de la normalidad tanto del conocer como del orden político-jurídico el modo en cómo el individuo y el soberano adquieren la función de puentes entre ambos mundos respectivamente.

"El instante aparece justamente por la relación de una decisión eterna con un instante diferente." La negación de este acto constitutivo nos lleva a un esquema formal autopoiético donde "si no fuera así, retornaríamos a lo socrático y no tendríamos ni Dios, ni decisión eterna, ni instante"21. El liberalismo, al proponer un gobierno de leyes, se acerca a una visión del mundo propia del deísmo, donde el legislador o Dios, rehúyen intervenir en el mundo, producto de un acto inicial, evitando los milagros o futuras situaciones de excepción. Al final esta filosofía desemboca en un árido ateísmo, donde un régimen formal constitucional hace pensar que el sistema legal se recrea a sí mismo.

La fe sería la excepción a lo general, en el caso kierkegaardiano, de lo ético; y trasladado a la lógica schmittiana, de lo normativo:

La fe consiste precisamente en la paradoja de que el Particular se encuentra como tal Particular por encima de lo general, y justificado frente a ello, no como subordinado, sino como superior. Conviene hacer notar que es el Particular quién después de haber estado subordinado a lo general en su cualidad de Particular, llega a ser lo Particular por medio de lo general, y como tal, superior a éste, de modo que el Particular como tal se encuentra en relación absoluta con lo absoluto ${ }^{22}$.

En Temor y temblor, el ejemplo de Abraham, quien con su fe logra afirmar lo Particular en tanto Particular, con el religare con lo Absoluto, deja al individuo por encima de lo ético, que sería lo general, de lo cual se escapa con gran angustia ${ }^{23}$. Por tanto, no puede encontrar el individuo ningún criterio o valor para decidir en un determinado momento; con la fe, en el amor a Dios, uno se supedita al supremo arbitrio, y queda únicamente la

${ }^{21}$ Søren Kierkegaard, Migajas filosóficas o un poco de filosofía, trad. de Rafael Larrañeta, Madrid: Trotta, 2007, pp. 40-41.

${ }^{22}$ Søren Kierkegaard, Temor y temblor, p. 46.

${ }^{23}$ Ibíd, p. 45. 
nuda voluntad para decidir. Aquella virtud teologal, lejos de implicar una toma de decisión, es apertura a la incertidumbre.

El caballero de la fe, otra figura aparecida en la obra anteriormente referida, por razón de su desvinculación con lo general, podría instaurar el orden nuevo del cual es él el único responsable. Esta idea del quijotesco andariego se acerca al soberano, que si bien busca el bien de lo general, ya no está supeditado a éste.

En la dictadura soberana, la cual instaura un nuevo orden, se encuentra un momento donde la bisagra entre lo jurídico y lo político se encuentra y un punto donde se une lo trascendente a lo inmanente. "[...] el particular está como tal por encima de lo general y se encuentra en relación absoluta con lo absoluto," ${ }^{24}$ es decir, tener fe no es sino arrojarse al absoluto. Por eso para Kierkegaard, sin fe, el sacrificio de Isaac sería ininteligible, y por tanto "Abraham está perdido" 25 . Las figuras del talante de Agamenón, que cita Kierkegaard, se remiten a lo general, y en este sentido es claro que ellos determinan, ante el cese de la normatividad más amplia, qué hacer en este momento de tensión, pero siempre recurren al interés público, a la preservación de la comunidad. Por tanto, no pasarían de ser, desde la óptica schmittiana, dictadores comisariales, es decir, agentes estatales que buscan, con medidas severas de mantener el statu quo amenazado.

Si se tienen en cuenta las variadas afinidades electivas entre la obra de Kierkegaard con la del jurista alemán Schmitt, se nos plantea una gran duda: ¿por qué no citó éste al teólogo danés en su gran obra Teología política? En páginas posteriores se hará un esbozo de las razones por las cuales el germano obviara mencionar al dinamarqués en su obra señera. Pero para esta labor es menester emprender un análisis de una temática desde la cual enjuiciaría el autor muniqués a Søren: el romanticismo político

\section{El romanticismo político; el liberalismo consecuente}

Para Carl Schmitt, la supuesta divergencia en el pensamiento de los denominados románticos políticos que, según los criterios de sus predecesores en el estudio del tema, no podía ser cabalmente comprendida, se entendía como producto de una mentalidad muy particular. El elemento común entre un Lord Byron filorepublicano y nacionalista, que incluso se

${ }^{24}$ Ibíd, p. 68.

${ }^{25}$ Ibíd. 
atrevía en tanto poeta a luchar contra los otomanos que dominaban sobre los griegos, y el escritor alemán Gentz, que era restauracionista y apoyaba la política filomonárquica del príncipe de Metternich, era una visión donde lo político quedaba anulado, producto de un arranque sentimental; donde cualquier objeto era meramente una ocasión para expresar el sentimiento, ya fuera aquél una mujer, un régimen o un lugar: el romanticismo político.

Este movimiento tan heterogéneo era producto, a juicio del jurista alemán, de dos grandes filosofías: el ocasionalismo de Malebranche, que al menos tenía a su favor tener a Dios como sumo referente y la filosofía del Yo de Fichte ${ }^{26}$. El romántico pervierte ambas filosofías y esto conduce a un mundo donde lo que prima es el sujeto, ensimismado en su propio yo, que sólo espera que su sentimiento hacia el mundo lo guíe en la toma de decisiones. Es incluso posible decir que más bien el romántico político sólo se deja fluir y encuentra en cualquier canal o vía el modo para expresar su ser. Si su existencia lo lleva a caer ya sea en el republicanismo ya sea en el monarquismo, eso es indistinto. Por eso Schmitt contrasta aquella visión del mundo con la propia de los tradicionalistas franceses: Luis Gabriel, vizconde de Bonald, Joseph de Maistre, entre otros, quienes asumían cabal y congruentemente el legitimismo monárquico de la Restauración y que no apoyaban causas ni nacionalistas ni republicanas, ni cedían su genio a las inspiraciones de la emoción ${ }^{27}$.

Los políticos románticos, si es que puede acuñarse un término así, no sólo se unen a una causa gracias a un emotivismo barato, sino que evitan cualquier resolución que pueda conllevar el asco o la angustia de la definición. Por eso sus posturas son cambiantes conforme pasa el tiempo y terminan por desechar principios que sólo adhirieron superficialmente. La irresolución es la característica de los políticos románticos; sin embargo, la política es elección de un partido, significa parcialidad. Por tanto, quien no toma una decisión, simplemente no es político. En ese sentido el liberalismo al ser constante discusión, sin concreción, ni resolución, también cae en la negación de esta esfera. Se puede incluso concluir que el romanticismo, en su suma irresolución, es la expresión máxima del pensamiento liberal, incluso, aquél es el liberalismo consecuente. La terquedad en no asumir una postura clara no es propia sólo de las posturas de los políticos románticos;

${ }^{26}$ Carl Schmitt, Romanticismo politico, trad. de Luis A. Rossi y Silvia Schwarzböck, Buenos Aires: Universidad Nacional de Quilmes Ediciones, 2000, pp. 110-112 y 148-149.

${ }^{27}$ Carl Schmitt, Romanticismo político, pp. 181-182. 
también hace mella la indecisión en otra clase de filosofías, de carácter dialéctico, que coronan las contradicciones con síntesis ulteriores.

Hay un elemento apolítico en las filosofías sintéticas, como la hegeliana, que incluso busca a propósito evitar la confrontación. Un ejemplo contemporáneo de esta filosofía de la eclosión y apolítica lo tenemos en esta cita de un filósofo mexicano:

Todo lo humano es dual: en esta frase está compendiada la filosofía que convirtió al siglo XX en el escenario más autoritario y sangriento de la Historia. Espíritu y materia, naturaleza y cultura, creacionismo y evolucionismo, capitalista y proletario [...], al aceptar la inevitabilidad de la confrontación se autorizaba la violencia como la única y verdadera vía evolutiva. La consecuencia de esta visión dual y confrontantiva ha sido la instauración de una dialéctica de odio como medio imperativo de proceder, pervirtiendo los valores y multiplicando las incertidumbres que nos condenan al temor ${ }^{28}$.

Leonardo da Jandra condena la violencia producto de la toma de partido, pero en su obra Filosofía para los desencantados busca una superación de la dualidad, a través de la síntesis, que sería el cosmocentrismo, una visión desde arriba, que logrará superar el choque entre egocentrismo y el sociocentrismo. Es notorio que el escritor radicado en el sur mexicano no se haya dado cuenta que las filosofías sintéticas, superadoras de las contradicciones, además de llevar a la anulación del individuo, también evitan la toma de partido que se requiere producto del vivir en una polis o entidad política, donde la res publica, lo que interesa a todos, siempre está en discusión. Como dijo Schmitt, lo político es la extensión de la guerra a otros escenarios. Es en la guerra, a través de la suma violencia donde la distinción base de lo político, la dicotomía amigo/enemigo alcanza su culmen.

Da Jandra al negar la violencia, niega lo político. Al autor sólo le perturba lo que le afecta a él directamente. En el plano del mero sentimiento. Es un idiota, en el sentido clásico, es decir, alguien cuya razón privada predomina sobre la razón general o política. En el mismo sentido el hegelianismo aparentemente hacía ver que desde un huevo primitivo había surgido la realidad, en un proceso tan radical como ver florecer una flor. Estas filosofías niegan la tensión de la toma de postura, y todo deviene confuso, ambiguo en el terreno de la polis, en la arena de la discusión pública. Semejantes filosofías, bien lo sabemos, molestaban mucho a Carl Schmitt, cuya obra fue una denuncia de la negación de lo político. Es probable que varios patrones

${ }^{28}$ Leonardo Da Jandra, Filosofía para desencantados, Girona: Atalanta, 2014, p. 105. 
y características de la obra del teólogo danés lo hicieran molesto para una mentalidad tan facciosa como la del germano. Sin embargo ¿fue tan radical su renuncia a admitir lo bueno y definitivo en Kierkegaard lo que llevó a Schmitt a omitirlo como autor de la cita más reconocida de su afamado trabajo Teología política?

\section{La omisión: razones para una descarada anulación}

La omisión de Schmitt de sus lecturas kierkegaardianas pudo deberse a ese espíritu romántico que denunció en su obra Romanticismo político. El romanticismo es el liberalismo por antonomasia. Schmitt cita a Kierkegaard en esta temprana obra suya. Lo refiere el jurista alemán como una persona, quien, imbuida del aparato literario romántico, sin embargo, escapa del ocasionalismo de los románticos, versión exagerada del liberalismo que siempre combatió Schmitt, y que les hace adoptar tantas banderas como elementos hermosos ven en el mundo. La anulación de lo político, de lo elemental, de lo distintivo fue el mal que siempre atacó Schmitt durante su vida. Al parecer Kierkegaard, a pesar de las palabras arriba mencionadas, nunca pudo escapar completamente del cargo de ser un autor romántico.

Si bien no menciona Schmitt a Kierkegaard en su gran obra Teología política, sí lo menciona en un pie de página de su texto Romanticismo político, el cual dice:

También había otra conclusión de la situación romántica, encontrada por Kierkegaard, el único grande entre ellos (pues a Kleist no lo incluyo entre los románticos). Todos los elementos del romanticismo político estaban activos en su obra: ironía, concepción estética del mundo, oposiciones entre lo posible y lo real, lo infinito y lo finito, el sentimiento del instante concreto. Su cristianismo protestante lo hacía un individuo aislado y que conscientemente existe en su relación con el Dios del cristianismo. En la inmediatez de la relación con Dios era superada toda comunidad humana por más valiosa que fuera como tal. Pero esta solución no entra en consideración por el romanticismo político ${ }^{29}$.

Ecos románticos son expresados por Kierkegaard en varias ocasiones, por ejemplo, cuando en la obra La repetición se habla del amante que

${ }^{29}$ Carl Schmitt, Teología política, trad. de Luis A. Rossi y Silvia Schwarzböck, Buenos Aires: Universidad Nacional de Quilmes Ediciones, 2000, p. 127 
dejó a su amada porque ya no encontraba en ella la ocasión para expresar su sentimiento, que no la amaba, que sólo encontró en ella un momento para desbocar su frenesí. He aquí algunos ejemplos del romanticismo kierkegaardiano:

La muchacha no era en realidad su amada, sino simplemente la ocasión que despertó en él la vena de la actividad creadora y lo convirtió en un poeta. Por esto mismo la amaba, por esto no la podía olvidar mientras viviese, ni nunca sería capaz de amar a otra mujer. Claro que, como hemos dicho, todo esto no significa que la amara, ya que solamente seguía suspirando por ella, consumido por su nostalgia ${ }^{30}$.

El amante,

[...] como es típico y normal en el caso de un poeta, no llegó nunca a tener ideas claras sobre lo que había hecho, cabalmente porque siempre ha titubeado en enfocar su actuación atendiendo a los aspectos exteriores y visibles de la misma o, mejor dicho, porque ha pretendido siempre enfocarla exclusivamente bajo esos aspectos que no ofrecen nunca una perspectiva adecuada y una pista segura $^{31}$.

De tener una postura más firme, que para Kierkegaard podría haber sido una base religiosa, el joven

habría actuado, desde luego, con mayor decisión y con unas fuerzas muy diferentes, aunque pagadas al precio de unos sufrimientos aún más atroces. Habría actuado con una consecuencia y una firmeza inquebrantables, y conseguido un incontestable hecho de conciencia en el que apoyarse constantemente, sin ninguna ambigüedad, sino de la manera más seria y segura, porque (si se adopta la postura religiosa), era un hecho basado en su relación con Dios ${ }^{32}$.

En esto encontramos otro puente con Kierkegaard, quien trata de escapar de la filosofía del fin de la historia de su época el hegelianismo. El apelar a lo trascendente salvo, por una fracción de materia, de convertirse en romántico. Ambos autores luchan contra el liberalismo de sus respectivas épocas: no por nada es extraño leer que Kierkegaard criticara a la recién

${ }^{30}$ Søren Kierkegaard, La repetición, trad. de Karla Astrid Hjelmstrom, Buenos Aires: JVE Psique, 1997, p. 9.

${ }^{31}$ Ibíd., p. 68.

${ }^{32}$ Ibíd. 
aparecida constitución liberal de Dinamarca en La enfermedad mortal. Incluso el adjetivo liberal aparece solamente una vez en ese texto para lanzar esa crítica política y teológica tan firme ${ }^{33}$. En una época posterior, Schmitt lidió con la difusión del liberalismo, primero en su país, durante la república de Weimar, después a través de su dispersión alrededor del orbe, producto de la derrota de las potencias del Eje durante la Segunda Guerra Mundial. Sin embargo, su obsesión contra el liberalismo no detuvo ni su avance, y para colmo ni siquiera logró que ambos se vieran libres de éste.

\section{La imposibilidad de superar el liberalismo}

Tanto Kierkegaard como Schmitt no lograron conjurar el peligro del relativismo liberal, solamente lograron agotar todas sus instancias antes de ver que no había un más allá axiológico al cual apelar. Con Schmitt, es más acuciado el relativismo ético. El soberano, al no encontrarse sometido al orden normativo, puede apelar, en situaciones de excepción a cualquier criterio o a cualquier valor que se le antoje para resolver la crisis. El hombre virtuoso de Aristóteles, que con su prudencia elige la mejor opción, les estaba vedado. Tampoco podía ninguno de los dos, so pena de perecer tanto el individuo como el estado, sumergirse en el espíritu trágico que llevó a Mainländer, a Larra y a otros a la única solución vital y ética viable para un mundo desprovisto de sentido: el suicidio. El cristianismo, en el primero el luteranismo y en el segundo el catolicismo, les impedía llegar a una solución tan radical.

Antes de continuar, debe quedar claro que se habla aquí de lo poco eficaces que son los modelos schmittiano y kierkegaardiano para resolver la cuestión ética; no se trata aquí de si ambos pensadores tomaron posturas claras sobre la realidad de su época, lo cual nadie objeta.

Según Kierkegaard, en La enfermedad mortal se plantean varios escenarios donde siendo el individuo un centro de confluencia tanto de lo finito como lo infinito, cae aquél en la desesperación ya sea al conformarse sólo con lo finito, ya sea al constituir un bien finito o material como infinito, ya sea al simplemente sentir que uno no puede superar los desafíos que implica

33 Søren Kierkegaard, Tratado de la desesperación, Librodot, S.A.E., versión digital en: https://static1.squarespace.com/static/58d6b5ff86e6c087a92f8f89/t/590d2c45d482e 9ff42ad1ef3/1494035526766/Kierkegaard\%2C+Soren+-+Tratado+de+la+desesperacion. pdf, consultada el día 7 de mayo de 2020, p. 62. 
aceptar lo infinito en el hombre. El tratado psicológico de Kierkegaard da cabida a la comprensión de las diferentes soluciones en las cuales un individuo trata de soportar su hastío. El escrito sólo nos arroja una aparente solución al problema de la desesperación, una postura: la fe. Sin embargo, en el resto de las decisiones trascendentes, el ser humano es dejado a su nuda voluntad, y en realidad, la fe es más una manera de ver el mundo, a través del lente de lo divino. Por eso incluso con la fe, uno se angustia, porque el ser humano se reconoce falible, débil, siente desesperación por causa de su incapacidad de cumplir con lo infinito que hay en él. Incluso para Kierkegaard de la duda, o de la crisis se sale por la libertad, ya que por ella uno entra al mismo escenario ${ }^{34}$. En conclusión, la mera voluntad.

A partir de la imposibilidad de escoger claramente un valor sobre otro, la nuda voluntad se erige como el único medio de salir del atolladero y, por tanto, aquí se cuela el dramatismo del pensamiento existencialista, que ve en Kierkegaard a su padre. En el sentido de las palabras de Kierkegaard, uno se lanza a la fe, como agotado por no encontrar algún modo de resolver la propia nada. Una vez secularizadas sus ideas sobre la desesperación, ya ni la fe pudo ir en auxilio de los meros individuos; de otro modo no se entendería la profusa literatura nihilista y existencialista que se basó en sus escritos o se hizo eco de sus tesis.

\section{Conclusiones}

Es patente que Schmitt ocultó sus vínculos intelectuales con Kierkegaard, pero debemos ahora reconocer la deuda de éste para con la teoría jurídicopolítica de aquél: la nuda voluntad junto con la imposibilidad de trascender el horizonte ético del liberalismo, condujeron a ambos a desarrollar sus ideas en el modo en que lo hicieron. Nuestra situación contemporánea, nos ha llevado, después de un periodo de aburrimiento, al desasosiego y ha hecho que Kierkegaard y Schmitt adquieran relevancia. La normatividad tanto ética como legal del liberalismo caduco posterior a la caída de la URSS ha llevado a los pueblos y a los individuos a replantearse sus más caras convicciones. Por eso estos dos autores hablan a nuestra época, que sólo puede despabilarse del tufo del extremo centro que ha dominado nuestras vidas y cuyos postulados habíamos aceptado con inercia, pero, para nuestra desgracia, y como decadentes que somos, sólo nos ayudan sus lecturas a ir

${ }^{34}$ Søren Kierkegaard, Johannes Climacus, o dudar de todas las cosas, p. 142. 
más allá del escenario de regodearnos en nuestro marasmo; eso al menos es lo que pensamos.

Tanto Kierkegaard como Schmitt se rebelan contra la sistematización, contra la formalización, contra la anulación de lo singular, de lo individual. En esta época donde a uno lo asfixian con sistemas tanto a la derecha como a la izquierda, estos dos autores adquieren un renovado interés.

Al enfatizar la voluntad, frente al predominio de la razón, tanto Kierkegaard como Schmitt socavaron las bases para la toma de una decisión, vaciaron el contenido de la misma. Lo importante no era ya el conocer para el pensador danés, ni lo conocido; tampoco para el alemán, lo era el contenido de la acción fundamental, un acto libérrimo o una constitución, ya la de Licurgo o la estadounidense; ambos suprimieron cualquier criterio para decidir entre una u otra opción. Si bien en Kierkegaard el relativismo moral queda reblandecido por el tema de la fe, no deja de ser patente que aquélla para el pensador danés es un aferrarse a Dios, un cambio de postura, pero no un criterio para afrontar cada crisis en la vida. El vaso comunicante más firme entre ambos pensadores, finalmente, no fue que el alemán leyera al danés, ni haber partido los dos de posturas trascendentes, sino responder a nuestro anhelo de encontrar un norte en medio de un mundo tan convulso y nihilista como el nuestro, aunque las respuestas aportadas por los dos pensadores centroeuropeos no fueran del todo adecuadas ni eficaces.

\section{Bibliografía}

\section{Obras de Søren Kierkegaard}

Kierkegaard, Søren, Jobannes Climacus, o De todo hay que dudar, trad. de Javier Teira Lafuente, Barcelona: Alba, 2008.

L La repetición, trad. de Karla Astrid Hjelmstrom, Buenos Aires: JVE Psique, 1997.

_ Migajas filosóficas o un poco de filosofía, trad. de Rafael Larrañeta, Madrid: Trotta, 2007.

Temor y temblor, trad. de Vicente Simón Merchán, Madrid: Tecnos, 2000.

— La enfermedad mortal (Tratado de la desesperación) Librodot, S.A.E, versión digital en https://static1.squarespace.com/static/58d6b5ff86e6c087a92f8f89/t/ 
590d2c45d482e9ff42ad1ef3/1494035526766/Kierkegaard\%2C+Soren++Tratado+de+la+desesperacion.pdf, consultada el 7 de mayo de 2020.

\section{Otras obras consultadas}

Agamben, Giorgio, El reino y la gloria, trad. de Flavia Costa, Edgardo Castro y Merces de Ruvituso, Buenos Aires: Adriana Hidalgo Editora, 2008.

Da Jandra, Leonardo, Filosofía para desencantados, Girona: Atalanta, 2014.

Jünger, Ernst y Heidegger, Martin, Acerca del nibilismo, trad. de José Luis Molinero, Paidós, Barcelona, 1994.

MacIntyre, Alasdair, Tras la virtud, trad. de Amelia Valcárcel, Barcelona: Crítica, 2001.

Schmitt, Carl, La dictadura, desde los comienzos de del pensamiento moderno de la soberanía hasta la lucha de clases proletaria, trad. de José Díaz García, Madrid: Revista de Occidente, 1968.

- Romanticismo político, trad. de Luis A. Rossi y Silvia Schwarzböck, Universidad Nacional de Quilmes Ediciones, 2000.

— Teología política, trad. de Luis A. Rossi y Silvia Schwarzböck, Buenos Aires: Universidad Nacional de Quilmes Ediciones, 2000.

Taub, Emmanuel, "Teología política, angelología y antropomorfismo: el problema de la secularización en el judaísmo" en Síntesis, revista de filosofía, no. 2, 2019, 132-149. 